\title{
Sensitivity Analysis of the Dynamic Behavior of a Salient-Pole Synchronous Machine Considering the Static Rotor Eccentricity Effect
}

\author{
I. Albino Padilla ${ }^{* 1}$, D. Olguín Salinas ${ }^{2}$, A. Román Messina ${ }^{3}$ \\ ${ }^{1,2}$ Department of Electrical Engineering, Instituto Politécnico Nacional \\ Instituto Politécnico Nacional Avenue, 07738 \\ Mexico City, Mexico \\ *dolguin47@yahoo.com \\ ${ }^{3}$ CINVESTAV Guadalajara \\ Científica Avenue 1145 \\ Zapopan, Jalisco, Mexico
}

\begin{abstract}
This paper presents the sensitivity analysis of the behavior of a synchronous machine using the winding function theory considering the effect of static air-gap eccentricity. The winding function theory as a method to calculate the inductances of synchronous machines from the geometry and the actual arranging of the windings is presented. Then, detailed numerical simulations are carried out to examine the impact of eccentricity on the steady state regimes. The important role of static eccentricity and its links with various symmetrical and asymmetrical operating conditions are discussed as well as its influence on the machine parameters and performance are investigated. Experimental and analytical parameter results are presented for a $60 \mathrm{~Hz}$, six-pole laboratory synchronous machine connected to an infinite bus under various static eccentricity conditions.
\end{abstract}

Keywords: Sensitivity analysis, static eccentricity, steady state regime, synchronous machine, unbalanced conditions, winding function.

\section{RESUMEN}

Este artículo presenta el análisis de sensibilidad del comportamiento de una máquina síncrona utilizando la teoría de función de devanado para considerar el efecto de excentricidad estática. Se presenta la teoría de función de devanado para el cálculo de las inductancias a partir de la geometría y del arreglo de los devanados. Se realizan simulaciones numéricas para analizar el impacto de la excentricidad en el estado estacionario. Se discute la importancia de la excentricidad y su relación con sus condiciones de operación simétrica y asimétrica así como la influencia sobre los parámetros y comportamiento de la máquina. Se presentan resultados experimentales y analíticos de una máquina de laboratorio de seis polos, $60 \mathrm{~Hz}$, conectada a un bus infinito bajo diferentes condiciones de excentricidad estática.

\section{Introduction}

During the last two decades, there has been great interest within the power system community in the diagnosis of faults in synchronous generators with static and dynamic eccentricities. As pointed out in the power systems literature, aspects such as quality of energy, efficiency, reliability, and security may be affected. A generator can suffer from damages due to static and dynamic eccentricity. Several authors have studied the effect of static and dynamic eccentricity on the dynamic performance of rotating machines and have devised ways to calculate the induction and synchronous machine parameters using the

winding function theory $[1,2,3,4]$ as well as electromagnetic studies $[5,6,7]$.

Aspects that have been studied include the analysis of machine behavior under healthy and eccentric rotor conditions, the effect of mixed static and dynamic eccentricity on machine inductances, and the detection of harmonics associated to rotor slots.

In [4], the dynamic behavior of an induction machine was studied under dynamic eccentricity conditions using the winding function approach. In their study, the authors take into account the 
skewing of the rotor bars and the resulting linear rise of the MMF across the slots to calculate the inductances of the motor. In $[8,9]$, the performance of a single and a three-phase induction motor was studied under mixed eccentricity conditions through the use of the winding function theory. In these studies, the inductances were obtained using the winding function theory. The analytical results were compared with those obtained from finite-element analyses.

The effects of rotor eccentricity (static and dynamic) on the behavior of the induction machine were studied in [10]. Using a finite-element model, the authors concluded that the circulating current between various combinations of parallel windings in an eccentric rotor induction machine reduces the unbalanced magnetic pull and significantly diminish or eliminate vibrations because of the magnetic force harmonics generated by the eccentricity.

Although much progress has been made in the development of analytical techniques for predicting machine parameters, few studies have actually compared the winding function approach with conventional test data obtained using conventional procedures. Furthermore, the dynamic performance of synchronous machines under various eccentric conditions has not been fully investigated.

This paper analyzes the behavior of a six, salientpole laboratory synchronous machine connected to an infinite bus based on simulations with a software developed in Fortran language [11,12].

\section{Eccentricity sources}

Rotor eccentricity occurs when the machine experiences a nonsymmetric air-gap distribution. This gives rise to unbalanced radial forces which can cause rubbing between rotor and stator resulting in a total damage. There are two different types of eccentricity: static and dynamic. The dynamic eccentricity is a condition in which the minimum radial air-gap rotates with the rotor. In the case of static eccentricity, the position of the minimal radial air-gap length is fixed in space.

Both eccentricities tend to coexist. In fact, a small level of static eccentricity exists in all machines, even in new ones because of manufacturing and assembling methods $[12,13]$.

Dynamic eccentricity can cause mechanical vibrations originated from the unsymmetrical distribution of the air-gap. However, this phenomenon is more difficult to detect in the case of static eccentricity; it has been reported that static eccentricity can be observed in old hydraulic machines because of the ovality of the stator core [12].

\section{Machine model}

The study is performed on a six-pole synchronous machine connected to an infinite bus, using flux linkages as state variables. Following the IEEE convention, the voltage and flux equations can be written as [12,14]

$$
\begin{aligned}
& {[V s]=-\frac{d[\Psi s]}{d t}-[R s][/ s]} \\
& {[V r]=\frac{d[\Psi r]}{d t}+[R r][/ r]} \\
& {[\Psi s]=[L s s][/ s]+[L s r][/ r]} \\
& {[\Psi r]=[L r s][/ s]+[L r r][/ r]}
\end{aligned}
$$

Noting that $[\Psi]=[L][I]$, and solving for $[I]$ the system of Equations (1), can be rewritten in the following form:

$\left[\begin{array}{l}V s \\ V r\end{array}\right]=\frac{d}{d t}\left[\begin{array}{c}\Psi \\ \Psi r\end{array}\right]+\left[\begin{array}{cc}R s & 0 \\ 0 & R r\end{array}\right]\left[\begin{array}{ll}L s s & L s r \\ L r s & L r r\end{array}\right]^{-1}\left[\begin{array}{c}\Psi s \\ \Psi r\end{array}\right]$

Furthermore, choosing flux linkages as state variables, Equation (2) becomes

$\frac{d[\Psi]}{d t}=[V]-[R][L]^{-1}[\Psi]$

The electromagnetic torque and mechanical equations for the machine are the following:

$$
\begin{gathered}
T_{e}=\frac{2}{3 \sqrt{3}}\left\{\psi_{a}\left(i_{c}-i_{b}\right)+\psi_{b}\left(i_{a}-i_{c}\right)+\psi_{c}\left(i_{b}-i_{a}\right)\right\} \\
\frac{d w_{r}}{d t}=\frac{w_{0}}{2 H}\left(T_{m}-T_{e}\right) \\
\frac{d \delta}{d t}=w_{r}-w_{0}
\end{gathered}
$$


where $T_{m}$ and $T_{e}$ are the mechanical torque, and the electromagnetic torque, respectively; $i_{a}, i_{b}$ and $i_{C}$ are the stator currents; $\psi_{a}, \psi_{b}$ and $\psi_{c}$ are stator flux linkages; $w$ is the angular speed; and $\delta$ is the load angle.

\section{Machine inductances under static eccentricity}

As discussed in the literature, the winding function theory uses machine physical design information such as the geometry and winding layout of the machine (number of slots, the air-gap length, the axial length of the machine) to calculate the behavior of the MMF across the air-gap, flux linkages and the associated machine inductances. According to the winding function theory, the mutual inductances between windings $i$ and $j$ under either static or dynamic eccentricity can be shown to be [2] the following:

$L_{i j}(\theta)=\mu_{0} r \int_{0}^{2 \pi} g^{-1}(\varphi, \theta) n_{i}(\varphi, \theta) N_{j}(\varphi, \theta) d \varphi$

where

$\begin{array}{ll}\mu_{0} & \text { permeability of free space } \\ l & \text { axial length of the machine } \\ r & \text { average radius of the air- }\end{array}$

gap

$g^{-1}(\varphi, \theta) \quad$ inverse air-gap function

Here, $N_{j}(\varphi, \theta)$ is the winding function of winding $\mathbf{j}$, $n_{i}(\varphi, \theta)$ is the turns function of winding $\mathrm{i}, \varphi$ is the angle along the inner surface of the stator, and $\theta$ is the angle of the rotor position with respect to a fixed point on the stator. Using the expressions for inductances from Equation (7), we obtain the following:

$$
\begin{aligned}
& L_{a a}=L_{4}+L_{5} \cos \left(6 \theta_{d}\right) \\
& L_{b b}=L_{4}+L_{5} \cos \left(6 \theta_{d}-4 \pi / 3\right) \\
& L_{c c}=L_{4}+L_{5} \cos \left(6 \theta_{d}+4 \pi / 3\right)
\end{aligned}
$$

where

$$
\begin{array}{ll}
L_{4}=L_{1}-L_{3} / 2 & L_{1}=\mu_{0} r I N h^{2} \pi g_{0} \\
L_{5}=L_{2}-L_{3} / 2 & L_{2}=\mu_{0} r I N h^{2} \pi\left(g_{6} / 2\right) \\
& L_{3}=\mu_{0} r I N h^{2} \pi\left(g_{3}{ }^{2} / g_{0} 2\right)
\end{array}
$$

Nh Number of turns per coil.

$g_{0} \quad$ D.C. component of the inverse air-gap function.

$g_{3} \quad$ Third harmonic of the inverse air-gap function.

$g_{6} \quad$ Sixth harmonic of the inverse air-gap function.

Details of this formulation can be found in [12]. Of particular significance and practical interest, Equations (8) reveal that the self-inductances of the stator phases can be represented by the sum of a constant component and a sixth harmonic term. A good agreement is found with the inductances derived by using conventional analyses (refer to Appendix A). Higher order harmonics are found to have a negligible impact on the behavior of the system and are neglected here. In interpreting these results, it should be emphasized that Equations (8) can also be used to calculate the inductances for the case with no eccentricity since in this case it can be proved that the third harmonic of the inverse air-gap $\left(g_{3}\right)$ is zero.

Based on the winding function approach, the machine inductances were calculated using geometric information and the physical arrangement of the windings. Table A3 in Appendix A shows the synthesized model structure and machine inductances for the stator windings corresponding to the case with no eccentricity and $50 \%$ eccentricity. Also of interest, Table A4 compares the results obtained using the winding function theory with the model obtained from short circuit tests.

\section{Simulation results}

\subsection{Balanced operating conditions}

Sensitivity analyses of the effect of machine parameters on the dynamic performance of the system were conducted. Static air-gap eccentricity in the salient-pole synchronous machine model was introduced by modifying the inductance matrix $[L]$ using Equations (8). In this analysis, only the self- and mutual inductances [Lss] of the stator were modified.

For clarity of illustration, simulations were conducted for two different modeling conditions: the machine with conventional machine inductances, and various levels of eccentricity with the machine model derived 
by the winding function approach. In these simulations, the machine operates for $1 \mathrm{~s}$ in steady state under no eccentricity conditions, using data obtained from short circuit tests [11]. At $t=1 \mathrm{~s}$, the stator inductance, $[L s s]$, is modified by introducing machine data obtained through the winding function theory. After the field flux reaches steady state at about $6 \mathrm{~s}$, various levels of static eccentricity $(10 \%$, $25 \%$ and $50 \%$ such as wear of bearings in an eccentricity-sensorless machine) were introduced to examine the sensitivity to the severity of static eccentricity. The simulation runs for 6 more seconds in order to observe the behavior of rotor flux linkages for the new machine parameters. The machine terminal voltages remain balanced.

Figures 1 through 3 show the effect of static airgap eccentricity on rotor fluxes, while Figure 4 shows the influence of variations on the level of eccentricity on the rotor load angle.

Simulations results indicate that static eccentricity has a significant influence on the behavior of the machine. As shown in Figures 1 through 4, the magnitude and variation of the rotor fluxes increase as the level of eccentricity increases. Also noticeable, the steady-state changes as the level of eccentricity increases. This is particularly noticeable for the machine load angle in Figure 4. These studies indicate the need for future calculations which more completely treat the role of static eccentricity on the behavior of the system and point to the need for improved characterization of machine inductances.

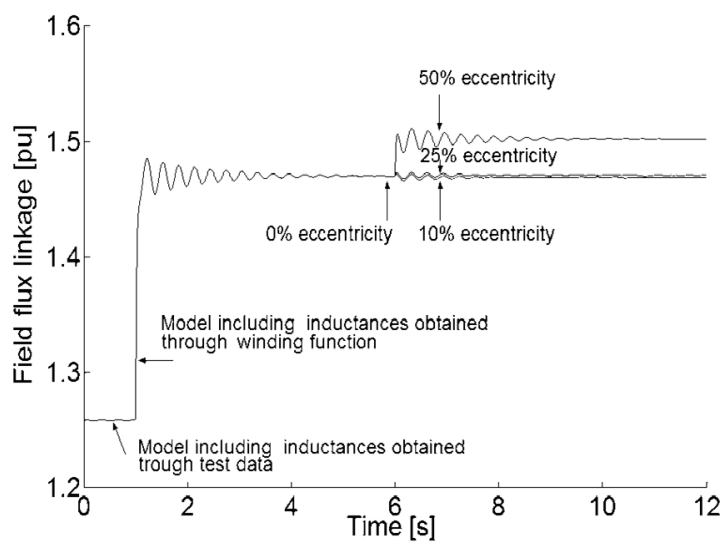

Figure 1. Dynamic behavior of field rotor winding, for various conditions of static eccentricity.

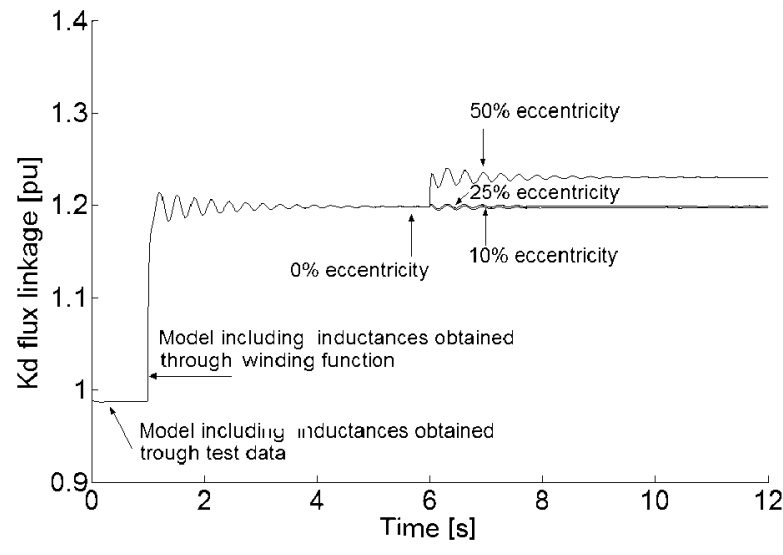

Figure 2. Dynamic behavior of the d-axis damper winding for various conditions of static eccentricity.

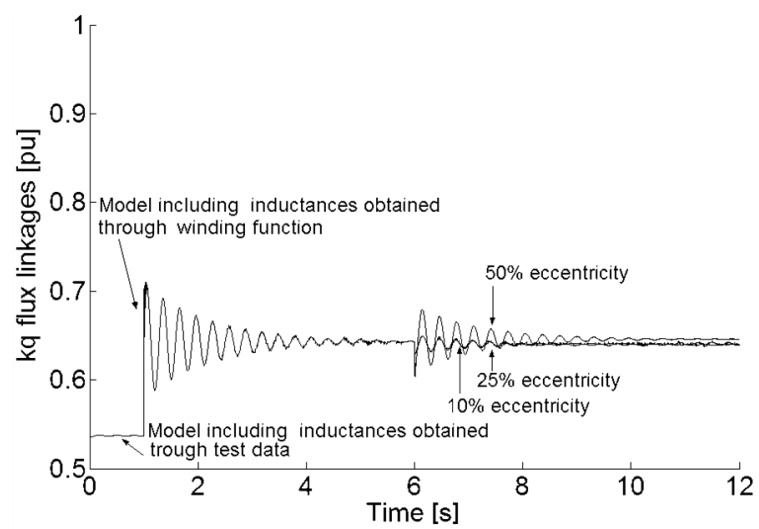

Figure 3. Dynamic behavior of damper winding on the quadrature axis for various conditions of static eccentricity.

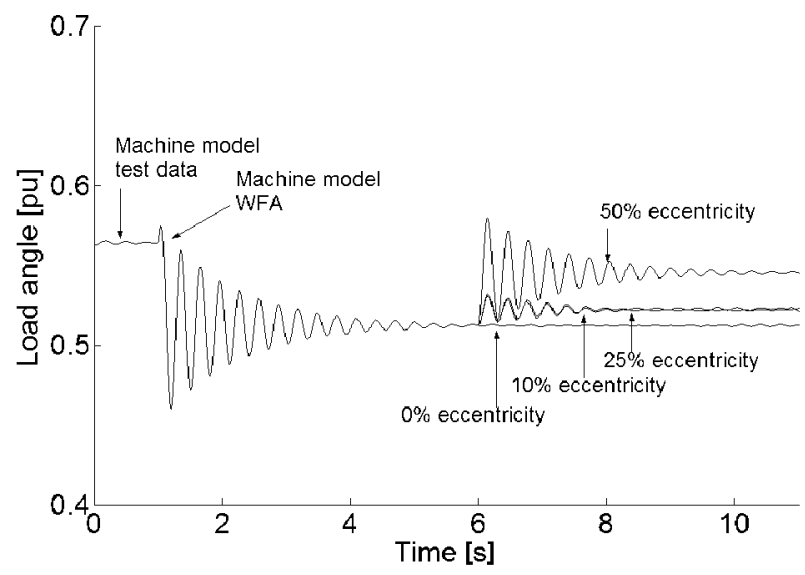

Figure 4. Dynamic behavior of the rotor load angle for various conditions of static eccentricity applied at $t=6 s$. 


\subsection{Unbalanced operating conditions}

In this study, the effect on rotor flux linkages was studied assuming unbalanced voltage operation under eccentricity. For this study, a value of 0.95 p.u. of the phase-a terminal voltage was considered, while the maximum values of the terminal voltages of phases $b$ and $c$ were kept at 1.0 p.u. The unbalanced voltage condition is applied at $\mathrm{t}=6.065 \mathrm{~s}$, while the eccentricity condition is applied at $t=6.0 \mathrm{~s}$. Again the simulation starts at $1 \mathrm{~s}$ with inductances derived by the short circuit test data; then [Lss] is modified by introducing data obtained by the winding function approach. Rotor flux linkages are studied for the cases with $0 \%$, $10 \%, 25 \%$ and $50 \%$ eccentricity. Plots of the field flux are given in Figures 5 and 6.

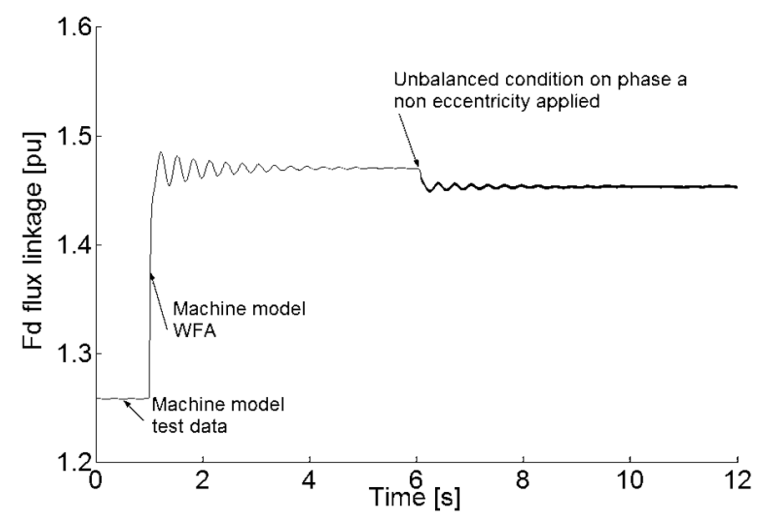

Figure 5. Dynamic behavior of rotor field winding with no eccentricity conditions, unbalanced condition in phase a applied at $\mathrm{t}=6.065 \mathrm{~s}$.

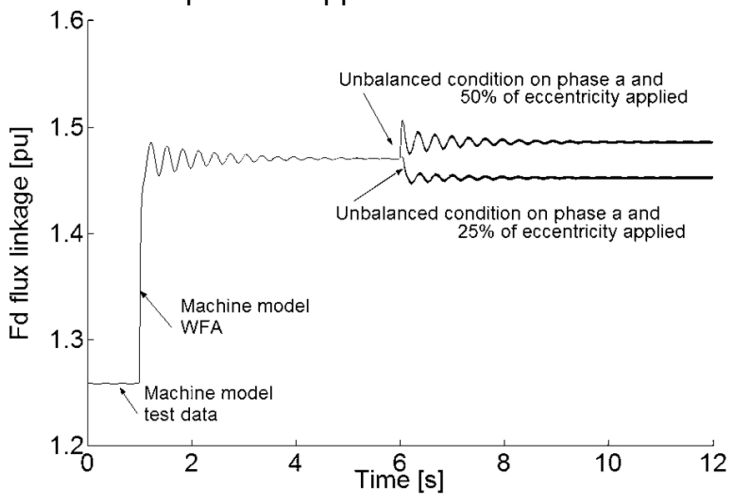

Figure 6. Dynamic behavior of rotor field winding with $25 \%$ eccentricity applied at $\mathrm{t}=6.0 \mathrm{~s}$, unbalanced condition in phase a $V_{m a}=0.95 \mathrm{pu}$ applied at $\mathrm{t}=6.065 \mathrm{~s}$.
As it is to be expected from physical intuition, the rotor flux oscillates because of the unbalanced condition on the bus terminals (refer to Figure 5). It should be emphasized that the steady-state equilibrium point changes when the eccentricity is applied. The same effect can be observed in the daxis damper winding flux.

Table 1 compares the relative percentage differences between equilibrium points for the case of $25 \%$ and $50 \%$ eccentricity relative to the case with no $(0 \%)$ eccentricity. Note that the percentage of difference increases as the severity of eccentricity is increased.

It can be seen in Figures 7 and 8 that the flux linkage on the quadrature axis under both, unbalanced conditions and with $0 \%$ eccentricity and $50 \%$ eccentricity, respectively, vary considerably.

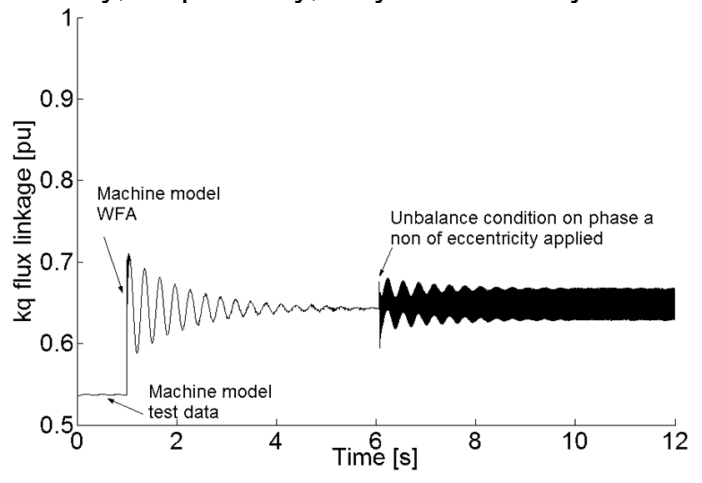

Figure 7- Rotor flux linkages for q-axis damper winding for the case with no eccentricity and unbalanced condition in phase a $V_{m a}=0.95$ p.u. applied at $\mathrm{t}=6.065 \mathrm{~s}$.

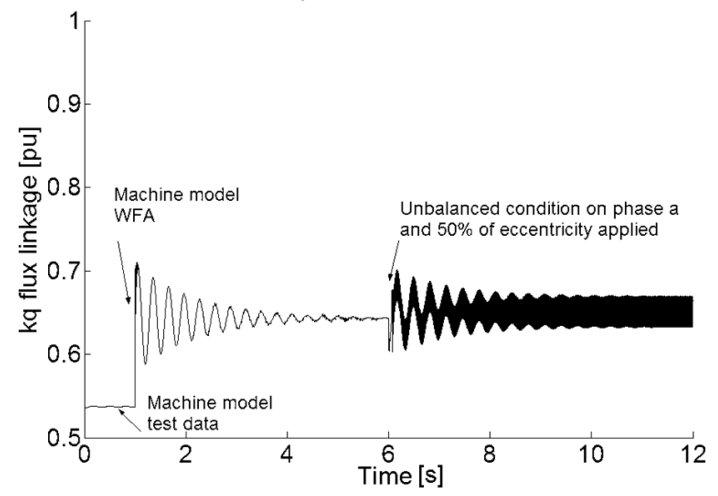

Figure 8. Rotor flux linkages for q-axis damper winding for the case of $50 \%$ eccentricity applied at $t=6.0 \mathrm{~s}$, and unbalanced voltage in phase a $\left(V_{m a}=0.95 \mathrm{pu}\right)$ applied at $\mathrm{t}=6.065 \mathrm{~s}$. 


\begin{tabular}{lll}
\hline$\%$ of Eccentricity & $\begin{array}{l}\% \text { of difference at the } \\
\text { equilibrium point }\end{array}$ & \\
\hline 25 & 0.11 \\
50 & 2.20 \\
\hline
\end{tabular}

Table 1. Equilibrium point difference on field winding.

\section{Conclusions}

The winding function approach is an important tool for the analysis of static eccentricity conditions. In this paper, this method was used to determine the synchronous machine parameters both, with and without static eccentricity. The effect of eccentricity on the performance of the system has been addressed based on simulations in which the parameters were obtained experimentally as well as theoretically.

Analytical and simulated results studies indicate that the static eccentricity in the salient-pole synchronous machine has a significant impact on machine performance. This is manifested by increased oscillations in rotor fluxes and different steady-state conditions. Further investigation is necessary to investigate the combined influence of static and dynamic eccentricity on larger real machine performance since they could play an important role in transient and small disturbance stability assessment. Also, more detailed studies are needed to validate the eccentricity simulated results with laboratory test measurements and to understand the origins of discrepancies between simulations performed using conventional data and data derived by the winding function approach.

\section{Appendix A. Machine description}

\begin{tabular}{lc}
\hline \multicolumn{1}{c}{ Output Power } & 5KVA \\
\hline Number of poles & 6 \\
Speed & $1200 \mathrm{rpm}$ \\
Number of slots & $54 \mathrm{slots}$ \\
Air-gap & $0.0014 \mathrm{~m}$ \\
Length & $0.125 \mathrm{~m}$ \\
Radius & $0.105 \mathrm{~m}$ \\
Turns on the stator winding 27 turns/coil \\
Turns on the rotor winding 317 turns/pole \\
Polar arc & $27.1^{\mathrm{O}}$ \\
\hline
\end{tabular}

Table A 1. Physical machine characteristics for laboratory machine[12].
Synchronous machine test data

\begin{tabular}{ll}
\hline Ra $=0.079$ Ohms & T'do $=67.0 \mathrm{~ms}$ \\
$H=0.658 \mathrm{~s}$ & T'"do=0.11ms \\
Direct axis & Quadrature axis \\
Xd = 1.80 Ohms & Xq=1.136 Ohms \\
X'd $=0.29$ Ohms & X"q $=0.126$ Ohms \\
X"d=0.26 Ohms & T"q=0.410 s \\
\hline
\end{tabular}

Table A 2. Machine parameters and time constants obtained through short circuit experimental tests [11].

\begin{tabular}{l}
\hline No eccentricity $(\mathrm{mH}) \mathrm{g}=0.0014 \mathrm{~m}$ \\
\hline$g_{0}=476(1 / \mathrm{m}), g_{6}=393 \mathrm{~m}(1 / \mathrm{m}), g_{12}=-196(1 / \mathrm{m})$ \\
$L_{a a}=12.5+5.1 \cos 6 \theta$ \\
$L_{a b}=12.5 / 2+5.1 \cos (6 \theta+\pi / 6)$ \\
\hline $50 \%$ eccentricity $(\mathrm{mH}) \mathrm{g}=0.0014 \mathrm{~m}$ \\
\hline$g_{0}=500(1 / \mathrm{m}), g_{3}=77(1 / \mathrm{m}), g_{6}=413(1 / \mathrm{m})$ \\
$L_{a a}=13.0+5.3 \cos 6 \theta$ \\
$L_{a b}=13.0 / 2+5.3 \cos (6 \theta+\pi / 6)$
\end{tabular}

Table A 3. Machine inductances calculated by the winding function approach.

\begin{tabular}{c}
$\begin{array}{c}\text { Inductances obtained by the winding function } \\
\text { approach }(\mathrm{pu})\end{array}$ \\
\hline$L_{a a}=0.9745+0.4023 \cos 6 \theta$ \\
$L_{a b}=-0.4873-0.4023 \cos (6 \theta+\pi / 6)$ \\
\hline Inductances obtained by short circuit test in (pu) \\
\hline$L_{a a}=0.9787+0.2213 \cos 6 \theta$ \\
$L_{a b}=-0.4893-0.2213 \cos (6 \theta+\pi / 6)$
\end{tabular}

Table A 4. Inductances obtained by winding function and short circuit test data [12]. 


\section{References}

[1] X. Kuo, Y. Liao, H. A. Toliyat, A. El-Antaby, and T. A. Lipo, "Multiple Coupled Circuit Modeling of Induction Machines," IEEE Transactions on Industry Applications, Vol. 31, No. 2, March/April 1995.

[2] H. A. Toliyat, M. S. Arefeen, and A. G. Parlos, "A method for Dynamic Simulation of Air-Gap Eccentricity in Induction Machines," IEEE Transactions on Industry Applications Vol. 32, No. 4 , July/August 1996.

[3] N. A. AL-Nuaim, and H. A. Toliyat, "A Novel Method for Modeling Dynamic Air Gap Eccentricity in Salient Pole Synchronous Machines," IEEE Transaction on Energy Conversion,Vol. 13, No. 2, June 1998.

[4] J. Gojko, M. Durovic, and O. Aleksandar, "Skew and Linear Rise of MMF Across Slot Modeling -Winding Function Approach," IEEE Transactions on Energy Conversion, Vol. 14, No. 3, September 1999.

[5] K. Ueda, T. Kumano, C. P. Riley, C. R. Emson, and D. A. Walsh, "Analytic Method of Electromagnetic Transient Phenomena of Rotational Machine and the Other Electric Machine caused by Power System Disturbances," IEEE Transactions on Magnetics, Vol. 34, No. 5, September 1998.

[6] C. Smith, and D. G. Dorrell, "Calculation and Measurement of unbalanced magnetic pull in cage induction motors with eccentric rotors. Part I: Analytical model," IEE Proceedings, Part B, vol. 143, no. 3, pp. 193202, May 1996.

[7] C. Smith, and D. G. Dorrell "Calculation and Measurement of unbalanced magnetic pull in cage induction motors with eccentric rotors. Part II: Experimental Investigations," IEE Proceedings, Part B, vol. 143, no. 3, pp. 202-210, May 1996.

[8] S. Nandi, H. A. Toliyat, and A. G. Parlos, "Performance Analysis of a Single Phase Induction Motor Under Eccentricity Conditions," IEEE Industry Applications Society Annual Meeting, New Orleans, Lousiana, October 5-9, 1997.

[9] S. Nandi, R. Mahan, and H. A. Toliyat, "Performance Analysis of a Three-Phase Induction Motor Under Mixed Eccentricity Condition," IEEE Transactions on Energy Conversion, Vol. 17, No. 3, September 2002.
[10] M.J. DeBortoli, S.J. Salon, D.W. Burrow, and C.J. Slavic, "Effects of Rotor Eccentricity and Parallel Windings on Induction Machine Behavior: A Study using Finite Element Analysis" IEEE Transaction on Magnetics, Vol. 29, No. 2, March 1993.

[11] D. Ruiz, T. Asiaín, and D. Olguín, "Teaching and Research Laboratory Simulator of Electric Power Systems," IEEE, FIE 99 Frontiers in Education, San Juan Puerto Rico November 1999.

[12] I. A. Padilla, "Effect on Transient Stability of Static Eccentricity in Salient Pole Synchronous Machine," M.S. Thesis-IPN SEPI IE ESIME, Mx. D.F. Mexico, October 2004.

[13] J.R. Cameron, W. T. Thomson, and A. B. Dow, "Vibration and current Monitoring for Detecting Air-Gap eccentricity in Large Induction Motors," IEEE Proceedings, pp.155-163,vol. 133, pt. B, No. 31986.

[14] Committee Report "Recommended Phasor Diagram for Synchronous Machines," IEEE Trans. PAS. Vol. 88, No. 111969. 